\title{
Working together to make Indigenous health care curricula everybody's business: a graduate attribute teaching innovation report
}

\section{keywords}

Indigenous health, nursing, midwifery, curricula, Australia, graduate attributes, collaboration

\begin{abstract}
Previously there has been commitment to the idea that Indigenous curricula should be taught by Indigenous academic staff, whereas now there is increasing recognition of the need for all academic staff to have confidence in enabling Indigenous cultural competency for nursing and other health professional students. In this way, Indigenous content can be threaded throughout a curriculum and raised in many teaching and learning situations, rather than being siloed into particular subjects and with particular staff. There are many sensitivities around this change, with potential implications for Indigenous and non-Indigenous students and staff, and for the quality of teaching and learning experiences. This papers reports on a collaborative process that was used to reconceptualise how Indigenous health care curricula would be positioned throughout a program and who would or could work with students in this area. Effective leadership, establishing a truly collaborative environment, acknowledging fears and perceived inadequacies, and creating safe spaces for sharing and learning were crucial in effecting this change.
\end{abstract}

\section{Introduction}

The inequity in the health and wellbeing of Australia's Indigenous peoples is well recognised in the literature (Couzos \& Murray, 2005; Maddocks \& Rayner, 2003; MacCrae et al, 2013; Turale \& Miller, 2006). One ongoing contributor to this inequity is the culturally inappropriate nature of mainstream health services that discourage Indigenous people from accessing healthcare (Turale \& Miller, 2006). Another well documented feature relates to the disadvantage experienced by Indigenous Australians in relation to their social determinants including economic opportunity, physical infrastructure, and social conditions (MacCrae et al, 2013). An essential factor in improving service provision to Indigenous peoples is a health workforce that is culturally sensitive and knowledgeable about how the history of colonisation, racism and oppression has impacted upon Indigenous people's health and wellbeing, and continues to do so.

The Australian Nursing and Midwifery Council [ANMC] called for all undergraduate nursing curricula to contain "a discrete subject, unit or module which provides educational preparedness in Aboriginal and Torres Strait Islander studies" (ANMC, 2007, p. 1). However, 
Fredericks (2006) has argued that this content needs to be threaded throughout all of the curricula and that it needs to evolve out of partnerships with Indigenous people. This paper describes a project where Indigenous and non-Indigenous academics have capitalised upon an Australian university's Graduate Attribute (GA) project to embed Indigenous cultural competency throughout all levels of health curricula.

\section{Background: Why a new approach was needed?}

In 2005, a national comparison of baccalaureate nursing degrees identified that one of the weaknesses of nursing curricula was minimal inclusion of information about Aboriginal and Torres Strait Islander peoples' health (Leibbrandt, Brown, \& White, 2005). This concern has been addressed by key nursing bodies such as the Australian Nursing Council, the Australian Nursing Federation and the Royal College of Nursing, through their release of position statements mandating the inclusion of Indigenous content in undergraduate nursing curricula (Goold \& Usher, 2006).

Although the amount of Indigenous health content has increased in nursing curricula over the intervening years, much of it has been characterised by deficit based approaches (Nakata, 2006). Institutions, through the support and hard work of Indigenous Australians working in health, are now recognising that it is vital to celebrate Indigenous culture, and focus on the strength and resilience of Indigenous people in teaching models to avoid perpetuating stereotypes (Committee of Deans of Australian Medical Schools, 2004; McGloin, Marshall, \& Adams, 2009; Woodall \& Stone, 2010). All of this is highly relevant to Health faculties in universities as, in order to prepare health care professionals to work safely and effectively with Indigenous peoples, they need to understand how the social determinants that are the legacy of ongoing colonisation and racism, have helped to create current health inequalities (Goold \& Usher, 2006; MacCrae et al 2013; Sherwood, 2009). There is therefore a need for the National Best Framework for Indigenous Cultural Competency in Australian Universities, (2011) to be urgently adopted by educational institutions, along with the recommendations and frameworks it has articulated.

In 1997, the Office of Aboriginal and Torres Strait Islander Health Service funded a forum, during which an Indigenous Nurses Forum was formed (Congress of Aboriginal and Torres Strait Islander Nurses (CATSIN), 2012). One of CATSIN's immediate recommendations for nursing education was that Indigenous content should be taught by Aboriginal and Torres Strait Islander people (CATSIN 2012). The mandate that Indigenous content be taught by Indigenous people stemmed from the recognition that Aboriginal and Torres Strait Islander 
people are the custodians of knowledges regarding their lives and culture (Partington, 2000), that Indigenous realities cannot be adequately portrayed by non-Indigenous Western paradigms (Nakata, 2006) and that cultural expertise is held by Indigenous academics (CATSIN 2012). However, it is unrealistic to expect an Indigenous academic (often only one) to be responsible for the cultural knowledge and competency of all students and staff in an entire faculty. The relatively small number of Indigenous academics means that to move ahead with this important work, many non-Indigenous academics also need to help students develop their knowledge, skills and professional cultural competency in order to make a real difference to the health and wellbeing of Indigenous Australians.

There are delicate tensions inherent for non-Indigenous academics in dealing with Indigenous subject matter. Whilst the non-Indigenous academic may be an experienced teacher in their chosen field, they are often novices regarding teaching Indigenous curricula and therefore may face similar challenges and fears to a new academic (Richardson \& Carryer, 2005). Indeed, non-Indigenous academics often fear that it is inappropriate for them to teach this subject matter (Partington, 2000; Williamson \& Dalal, 2007). Common concerns include: "What if I say the wrong thing?; I don't want to offend anyone; Am I skilled enough to mark assessments of Indigenous content?". This range of very legitimate anxieties presents a challenge too for Indigenous academics who may be assisting non Indigenous teaching colleagues through the minefield of cultural safety (Gallavan, 2007; Walker, Cromarty, Kelly, \& St Pierre - Hanson, 2009) with a commonly accepted definition of cultural safety being, "an environment which is safe for people; where there is no assault, challenge or denial of their identity, of who they are and what they need. It is about shared respect, shared meaning, shared knowledge and experience, of learning together with dignity, and truly listening" (Williams, 1999, p. 213).

The issues are also serious from the student perspective. Indigenous students have reported discriminatory practices and breaches of cultural sensitivity when being taught about Indigenous culture by non-Indigenous academics (Kippen, Ward, \& Warren, 2006; Turale \& Miller, 2006; West, Usher, \& Foster, 2010). Lack of understanding, or offensive comments by other students that are ignored or poorly dealt with also have a strong impact on both Indigenous and non-Indigenous students. The lack of explicit responsibility for the development and teaching of Indigenous elements of the curriculum by non-Indigenous academics can manifest as weak engagement or interest in either developing students, or dealing with unacceptable behaviour. Indigenous curricula, knowledge and skills are seen as somebody else's business (Goold \& Usher, 2006). 
The realisation that Indigenous Education is actually everyone's business has recently become clear: everyone is now required to take up this responsibility (University of XXXX, 2011). Without adequate preparation, however, academic staff may inadvertently distort Indigenous knowledges (Nakata, 2004) and cause offence or hurt to Indigenous students and staff. Therefore, respectful collaboration between Indigenous and non-Indigenous academics remains crucial. This paper discusses the formation and actions of a working party that set out to address this challenge in a health based faculty of an urban Australian university.

\section{Using graduate attributes curriculum development to create change}

A university wide project provided an important opportunity for the faculty to reflect upon and reconceptualise Indigenous curricula: its nature and how it is taught across all course levels. This project's framework and resources have provided the space to actively, and intuitively respond to current policy and strategies for Indigenous education and employment. The Graduate Attribute (GA) Project requires that Graduate Attributes be developed and embedded in all courses and constructively aligned (Biggs, 2003a) from course level, through subjects, to assessment tasks and criteria. The framework for implementing the GA project draws on the principle of constructive alignment (University of Technology, 2012, Biggs, 2003b). Students need to construct their own knowledge and this requires that all aspects of their learning environment be aligned. Our intentions are that for students' learning, the teaching and learning activities they engage in, including the assessment of learning outcomes, all need to be carefully and explicitly linked. When "assessment is organized holistically across subjects and programs with complementary integrated tasks" (Boud, 2010, p. 2) students are able to understand what is required of them in a subject and there are clear connections between subject requirements, subject content and subject assessment.

\section{The Indigenous Graduate Attribute Project aims}

In order to move forward an Australian Faculty of Health has developed a collaborative process built around the university's GA project. The aims of this project were to:

1. develop a framework to ensure that Indigenous content is effectively embedded, implemented and evaluated in health curricula at all levels

2. position Indigenous curricula and cultural competency as everyone's business

3. identify and implement strategies that will facilitate the enhancement of culturally safe teaching and learning spaces for Indigenous and non-Indigenous students and staff 
4. develop appropriate resources that help all staff to become more competent and feel supported in developing Indigenous competency.

The key elements that were put into place to create the shift in perspectives and skills required in the Faculty of Health follow.

\section{Starting at the Beginning with People: Establishing the working party}

This project was undertaken within a large university faculty that provides multiple health programs. To deliver the aims of this project it was essential to focus on developing a meaningful collaborative process for progression of work. This was realised through the building of a safe environment for exploring intercultural and cross-cultural information. In order to achieve this safe environment, a number of processes were used. Initially, targeted invitations were sent to key stakeholders across both the faculty and university to form a working party. This group consisted of Indigenous academic staff members, language, learning and curriculum development academics and other interested personnel. At the first meeting a focus on key areas of work for progression was discussed and outlined. Four areas of priority were identified (with ongoing reflection and adaptation over time) and these were the development of:

1. a graduate attribute focusing on professional cultural competence to enable health graduates to work respectfully with Aboriginal and Torres Strait Islander people

2. a context statement to articulate the importance of this work for the faculty

3. a core set of course learning outcomes to assist program staff with their curricula alignment

4. key resources and processes to support non-Indigenous staff to teach Indigenous content in a safe way, to transform thinking and enable students to develop the articulated graduate attribute

The initial meeting revealed a common goal, which was to acknowledge, confront and make a difference to the significant inequities that sustain the unacceptable health status of Indigenous Australians. A frank and informed approach was undertaken with discussions and dialogue shared by experts in the field, with specific reference to the ongoing effects of colonisation and racism. At all times, a strong focus on the need to provide education focusing on the strengths of Indigenous Australians and hopes for a shared future was held.

Strong leadership was required and utilised to shift the agenda from further problematising of Indigenous Australians, this being an often successfully used strategy by non-Indigenous 
peoples to deflect from actively participating in a positive agenda regarding Indigenous Australians (Sherwood, 2009). The leadership within this Project was greatly appreciated by members of the working party, particularly Indigenous members, as their energies are often used up having to provide basic information and education before they can move on to effect any change (Asmar \& Page, 2009; Laycock, Walker, Harrison, \& Brands, 2009; Nakata, 2006).The strong leadership was an important component of what grew into a very effective process where any elements of ignorance and prejudice were replaced by engagement and respect.

As described by Linden (2003) collaboration is required where complex issues need to be worked through to enable progression, resolution and / or change. However, many times people across agencies, teams, departments or similar meet without collaborative effect by meeting together but still working alone (Linden, 2003). The working party never made changes to previously agreed work without the full team being aware via email or face-to-face discussion enabling a true vision for shared working which remains to the present day. Outcomes were achieved at every meeting, alongside expectations of concrete contributions from each member of the group involved. From the commencement of the project, the working party owned both the content and process for the work underway and continues with this approach. Linden (2003) describes the notion that a group may not have one leader but rather an abundance of leadership and this was demonstrated within the group. All members of the group brought differing expertise and experience, whether that be Indigenous ways of knowing, being and doing; teaching and learning; research; curriculum development; project management skills and/or clinical knowledge. All of these were equally important and valued. A shared vision and strength of conviction was what enabled this collaboration to flourish and this has driven achievements to date. The fundamental shared ownership underpins the group and continues to support the implementation of this work as it is rolled out across the Faculty.

Building an environment of safety centres on respect, openness, the building and nurturing of relationships, honesty and the philosophy of social justice for all and the working party succeeded in developing a connectedness to enable this. This was achieved through honouring the time to listen to each other's perspectives and focusing on the aims of a positive and shared future for Indigenous and non-Indigenous Australians. "Through the modelling and practice of connected relationships between Indigenous and non-Indigenous 'educators' in all our courses we hope to demonstrate dialogical spaces and embody what we teach" (Sherwood, 2011, p. 109). This sense of safety enabled learning for all working party members and this has translated into supports to allow greater learning for all academics with the belief that "teachers are better able to nourish the learning spirit of students when they understand 
themselves" (Anuik \& Gillies, 2012, p. 63). Therefore, developing a graduate attribute and process for embedding and supporting this that centres on open dialogue, innovation and the development of social justice is supportive for all staff and students alike (Sherwood, 2011).

\section{Developing the key strategies}

Once a safe and collaborative space was formed to enable progression of our articulated aims, the following key strategies became a point of focus:

1. Leadership to support progression of this work Faculty wide

2. Supporting Indigenous and non-Indigenous academics to feel safe and competent with the material they are teaching

3. Enabling an authentic Indigenous voice in the classroom (with or without a class led by an Indigenous academic).

These three points are being addressed concurrently and all evolve from a focus on the development of a faculty wide graduate attribute that all faculty programs will progressively implement at course and subject levels. There is a desire to achieve the faculty-wide goal that graduates have professional cultural competency which contributes to the health and wellbeing of Indigenous Australians, inclusive of physical, social, emotional and spiritual wellness (Faculty of Health, 2013). The initial decision to develop a faculty based attribute rather than a program level one, set the scene for future working successes through allowing authentic Indigenous voices to lead in the writing of this attribute and resources following on from this. The process for embedding this Graduate Attribute (GA) included staff and stakeholder input, refinement and finalisation of course and subject level objectives and mapping throughout all curricula inclusive of assessment criteria. Authenticity of content delivery is a consistent area of concern for all and this remains a key priority for the working party. As a result, a resource kit is under development to provide guidance, including appropriate literature, resource materials, examples of teaching and learning activities, along with ideas for assessment that have all been reviewed and led by Indigenous academics. However, it is important to note that the utility of resources relies on the structures and processes they sit within. Therefore, a range of steps have been taken (Table 1) and several more will continue to be made to ensure this work grows in the years ahead. Of note are the Faculty Yarning Circles, commenced in 2013, to enable a safe space for academic staff to explore their own learning of Indigenous ways of knowing, being and doing. These yarning circles run monthly on a focused topic area, and are facilitated by an Indigenous member of staff. 
The GA project, which commenced in 2012 , has provided a unique and timely opportunity to work with key Indigenous academic staff within the University. Prior to this, the Indigenous elements of subjects and courses was sporadic and mostly limited to single dedicated core subjects taught in undergraduate Nursing and Midwifery programs. These core subjects were relied upon to achieve Indigenous outcomes, with many staff presuming that all content was covered elsewhere and that they did not have to consider this at all; that it was not their business. As a result of the faculty's new commitment to a faculty wide Indigenous Graduate Attribute, a significant step forward in acknowledging the significance and importance of Indigenous cultural competence within the health disciplines has been made and a shift in understanding that this important area is everybody's business is underway.

The process implemented within the faculty for aligning this attribute relied on extensive work by the working party and curriculum developers followed by the faculty's project manager working with each program team. This program team had to determine in which subjects the attribute and three related course learning outcomes (that are a detailed articulation of key outcomes required to develop this attribute) would be embedded and how students' skills and knowledge progressively developed across a course. At each phase of the process, staff were provided with opportunities and a space for discussion and time to reflect on this work along with resources, guidance and support from the project manager. Staff engagement in this process has been strong and has enabled them to embed this graduate attribute through to the marking criteria for appropriate subjects. This work has been achieved within four programs, with others about to commence this same process. The next phases of the project will involve review and evaluation of the levels of student achievement and this will provide an opportunity to refine and review the alignment of this graduate attribute in the faculty's courses.

A number of strategies were employed to progress this work. As previously outlined, there were calls for expressions of interest to join the working party. This group engaged in a collaborative discussion process over several meetings to develop the graduate attribute. The first draft was piloted with a program team who were already engaged in the GA process (as this is a staged process for the faculty) and provided key feedback indicating that a context, or background statement to address the intent of the Indigenous GA would be helpful, particularly to external stakeholders who were asked to provide feedback on draft program GA's. The second draft of the Indigenous graduate attribute included this context statement (provided in Table 2) which received positive feedback and was incorporated. The working party also joined the broader Health GAP reference group meetings as a strategy to ensure that the Indigenous Graduate Attribute development process was not separated from the wider faculty context. A faculty GA newsletter (News: GAP) was another important means of 
communication to staff, particularly for staff from those programs that had not yet commenced the development of graduate attributes in their courses.

The working party also identified the need to disseminate this work beyond the faculty and so a presentation was made to the University's Teaching and Learning Forum day (Virdun, Gray, \& Sherwood, 2012) to highlight the development of this graduate attribute. News: GAP was, in addition, circulated to the University and Faculty Graduate Attribute Project Teams to inform development of Indigenous Competence in line with university policy. The overall progress in embedding the GA in courses was shared so that successful aspects of the process and experiences, and any adjustments or rethinking that had been required, were built upon. The scale of this change within the faculty and all its courses has meant that it is both critical to recognise the hard work underway, as well as maintain the excitement and anticipation regarding this important attribute for students.

\section{Recommendations: Where to next?}

It is anticipated that experiences gained within the current project could resonate with other faculties who might be considering addressing Indigenous cultural competency in course curricula and teaching and learning. Critical to the process is the creation of a safe space within which to share ideas and learn from one another, enable Indigenous voices to be heard and to lead change. Through the process of developing the Indigenous graduate attribute ownership of a common goal was established based on a fundamental understanding of shared working, that this is everybody's business. In addition, there is acceptance that this space is not static and that as the project enters different phases the nature of the work will evolve. However, the necessary constant is close and ongoing work with Indigenous leaders to ensure that the project retains its integrity and Indigenous voices continue to be privileged in the transmission of Indigenous knowledges.

Further efforts are now being directed toward engaging the rest of the faculty in this shared vision for the future. This will be achieved through the careful selection of appropriate resources to support lecturers in including Indigenous curricula as well as the ongoing yarning circles and cultural safety training. As we implement this new approach to cultural competency we need to ensure that staff are culturally safe, as well as having a solid working knowledge of each of the key areas of focus. Mechanisms to allow students and staff to be involved and help to evaluate progress are under development.

\section{Conclusions}


In this paper the importance of establishing strong and respectful collaborations in achieving effective and authentic Indigenous health care curricula and ensuring that academic staff view such content as everybody's business, are highlighted. This paper discusses the formation and actions of a working party of the graduate attributes project in a health based faculty of an urban Australian university. Inclusivity for all members of the working party was essential given representation included those working across university departments and from varying professional roles. Achieving inclusivity involved sensitive chairing of meetings, equity of membership status, ongoing feedback in between meetings on progress and respect for all statements made. It became clear that the development of a safe working environment for all members was fundamental to the successful work progression. It is less certain whether collaboration preceded or evolved within the safe environment. However, what became evident was that in addition to being well-intentioned, the collaboration of the group was a powerful catalyst for change. Having successfully developed such a space is a great achievement, how to maintain this is an ongoing focus and investment in order to realise the faculty's vision of all graduates making a positive difference to the physical, social, emotional and spiritual wellness of Indigenous Australians. 


\section{References}

ANMC. (2007). Inclusion of Aboriginal and Torres Strait Islander peoples health and cultural issues in courses leading to registration or enrolment. Canberra ACT.

Anuik, J., \& Gillies, C. (2012). Indigenous Knowledge in Post-Secondary Educators' Practices: Nourishing the Learning Spirit. Canadian Journal of Higher Education, 42(1), 63-79.

Asmar, C., \& Page, S. (2009). Sources of satisfaction and stress among Indigenous academic teachers: findings from a national Australian study. Asia Pacific Journal of Education, 29(3), 22-32.

Biggs, J. (2003a). Aligning teaching for constructing learning Retrieved from www.heacademy.ac.uk/resources/detail/resource database/id477 aligning teaching for constructing learning

Biggs, J. (2003b). Teaching for quality learning at university (2 ed.). Buckingham: Open University Press/Society for Research into Higher Education.

Boud, D. (2010). Assessment 2020: Seven propositions for assessment reform in higher education. In A. L. a. T. Council (Ed.). Sydney.

Committee of Deans of Australian Medical Schools. (2004). CDAMS Indigenous health curriculum framework. Melbourne.

Congress of Aboriginal and Torres Strait Islander Nurses. (2012). National Aboriginal and Torres Strait Islanders nursing forum an initiative to develop strategies for the recruitment. Retrieved 10th March, 2013, from http://catsin.org.au/about-us/forum/

Couzos, S., \& Murray, R. (2005). Aboriginal Primary Health Care. An Evidence-based Approach (Second ed.). Victoria, Australia: Oxford University Press.

Faculty of Health, XXXX., Sydney. (2013). Indigenous Graduate Attribute. Sydney.

Fredericks, B. (2006). Which way? Educating for nursing Aboriginal and Torres Strait Islander peoples. Contemporary Nurse, 23(1), 87-99.

Gallavan, N. (2007). Seven perceptions influencing novice teachers 'efficacy and cultural competence. Journal of praxis in multicultural education, 2(1), 6-22.

Goold, S., \& Usher, K. (2006). Meeting the health needs of Indigenous people: how is nursing education meeting the challenge? Contemporary Nurse, 22(2), 288-295.

Kippen, S., Ward, B., \& Warren, L. (2006). Enhancing Indigenous participation in higher education health courses in rural Victoria. The Australian Journal of Indigenous Education, 35(1), 1-10.

Laycock, A., Walker, D., Harrison, N., \& Brands, J. (2009). supporting Indigenous researchers: a practical guide for supervisors (1st ed.). Darwin: Cooperative Research Centre for Aboriginal Health.

Leibbrandt, L., Brown, D., \& White, J. (2005). National comparative curriculum evaluation of baccalaureate nursing degrees: a framework for the practice based professions. Nurse Education Today, 25(6), 418-429.

Linden, R. M. (2003). Working across boundaries: Making collaboration work in government and nonprofit organizations: Jossey-Bass.

Maddocks, I., \& Rayner, R. (2003). Issues in palliative care for Indigenous communities. Medical Journal of Australia, 179, S17 - 19.

MacRae A, Thomson N, Anomie, Burns J, Catto M, Gray C, Levitan L, McLoughlin N, Potter C, Ride K, Stumpers S, Trzesinski A, Urquhart B (2013). Overview of Australian Indigenous health status, 2012. Retrieved 15.07.13 from http://www.healthinfonet.ecu.edu.au/healthfacts/overviews

McGloin, C., Marshall, A., \& Adams, M. (2009). Leading the way: Indigenous knowledge and collaboration at the Woolyungah Indigenous centre. Journal of University Teaching and Learning Practice, 6(2), 1-15.

Nakata, M. (2004). Ongoing conversations about Aboriginal and Torres Strait Islander research agendas and directions. The Australian Journal of Indigenous Education, 33(1), 1-6.

Nakata, M. (2006). Australian Indigenous studies: a question of discipline. The Australian Journal of Anthropology, 17(3), 265-275. 
Partington, G. (2000). Non-Indigenous academic and Indigenous autonomy. The Australian Journal of Indigenous Education, 28(2), 15-18.

Richardson, F., \& Carryer, J. (2005). Teaching cultural safety in a New Zealand nursing education program. The Journal of nursing education, 44(5), 201.

Sherwood, J. (2009). Who is not coping with colonisation? Laying out the map for decolonisation. Australiasian Psychiatry, 17 Supplement(1), S24-S27.

Sherwood, J., Keach, S., Keenan, T. \& Kelly, B. (2011). Indigenous studies: Teaching and learning together, in N. Purdie, G. Milgate and H. R. Bell (Eds.), Two way teaching and learning. Toward culturally reflective and relevant education. Camberwell: ACER Press.

Turale, S., \& Miller, M. (2006). Improving the health of Indigenous Australians: reforms in nursing education. An opinion piece of international interest. International Nursing Review, 53(3), 171-177.

Universities Australia. (2011). National Best Practice Framework for Indigenous Cultural Competency in Australian Universities. Canberra, ACT.

University of XXXX. (2011). Indigenous Education Strategy 2011 - 2014.

University of XXXX. (2012). Framework used in the Graduate Attribute Project. from http://www.iml.uts.edu.au/curriculum/framework.html

Virdun, C., Gray, J., \& Sherwood, J. (2012). Developing a Graduate Attribute to embed Professional Cultural Competency for Indigenous Australians throughout Curricula in the Faculty of Health. Paper presented at the XXXX Teaching and Learning Forum, Sydney.

Walker, R., Cromarty, H., Kelly, L., \& St Pierre - Hanson, N. (2009). Achieving cultural safety in Aboriginal health services: implementation of a crosscultural safety model in a hospital setting. Diversity in health and care, 6(1), 11-22.

West, R., Usher, K., \& Foster, K. (2010). Increased Numbers of Australian Indigenous Nurses Would Make a Significant Contribution to 'Closing the Gap' in Indigenous Health: What Is Getting in the Way? Contemporary Nurse, 36(1-2), 121-130.

Williams, R. (1999). Cultural safety-what does it mean for our work practice? Australian and New Zealand Journal of Public Health, 23(2), 213-214.

Williamson, J., \& Dalal, P. (2007). Indigenising the curriculum or negotiating the tensions at the cultural interface? Embedding Indigenous perspectives and pedagogies in a university curriculum. The Australian Journal of Indigenous Education, 36(S), 51-58.

Woodall, H., \& Stone, K. (2010). Indigenous health education at the ANU: A reflection. Medical Student Journal of Australia, 2(2), 44-45. 
Table 1: Steps taken to ensure this work grows over time

\begin{tabular}{|l|l|}
\hline Step 1 & $\begin{array}{l}\text { The establishment of an ongoing safe and truly collaborative working } \\
\text { environment }\end{array}$ \\
\hline Step 2 & $\begin{array}{l}\text { The decision to develop a Faculty wide graduate attribute (the only one } \\
\text { developed at a Faculty level) }\end{array}$ \\
\hline Step 3 & $\begin{array}{l}\text { The leadership at Program level to assist curricula change to enable the } \\
\text { development of this Faculty attribute }\end{array}$ \\
\hline Step 4 & $\begin{array}{l}\text { The openness of staff to express their fears and perceived inadequacies in } \\
\text { teaching content related to our Australian Indigenous history and current day } \\
\text { truths }\end{array}$ \\
\hline Step 5 & $\begin{array}{l}\text { The 'can-do' attitude of the working party to acknowledge these fears and } \\
\text { develop strategies to assist inclusive thus far of regular 'yarning circles', } \\
\text { cultural awareness training, a resource kit and a workshop }\end{array}$ \\
\hline Step 6 & $\begin{array}{l}\text { The acknowledgment of the working party and staff that this will all remain } \\
\text { a work in progress and requires ongoing focus and energy for successful } \\
\text { progression }\end{array}$ \\
\hline
\end{tabular}

Table 2

\section{Context statement for the Faculty Graduate Attribute}

The Faculty of Health considers Aboriginal and Torres Strait Islander peoples' health to be everybody's business, and acknowledges that ongoing colonisation and racism are vital determinants impacting on the health of Indigenous peoples. We are therefore committed to supporting all staff and students to develop new knowledge and skills that will enable meaningful engagement with Indigenous peoples, communities and their organisations (Faculty of Health, 2013). 